\title{
Prognosis of COVID-19 Patients Requiring Intensive Care Unit Care
}

\author{
Hülya Sungurtekin ${ }^{1, \star}$, Ülkü Arslan ${ }^{1}$, Cansu Özgen ${ }^{1}$, \\ İsmail Hakkı Akbudak ${ }^{2}$, Mithat Kahramanoglu ${ }^{1}$, Hakan Erbay ${ }^{1}$, \\ Habip Atalay ${ }^{1}$, Ahmet Çalişkan ${ }^{3}$, Simay Karaduman ${ }^{1}$
}

\begin{abstract}
${ }^{1}$ Department of Anesthesiology and Reanimation, Critical Care Unit, Pamukkale University, Denizli, Turkey ${ }^{2}$ Department of Internal Medicine, Pamukkale University, Denizli, Turkey ${ }^{3}$ Department of Medical Microbiology, Pamukkale University, Denizli, Turkey
\end{abstract}

\section{*Correspondence}

hsungurtekin@yahoo.com

(Hülya Sungurtekin)

\begin{abstract}
Background: There is gobal concern regarding the prognosis of COVID-19 patients requiring care in the Intensive Care Unit (ICU). The aim of this study is to report the demographics, clinical features, comorbidities, imaging findings, and prognosis among critically ill patients with COVID-19 in the ICU. Methods: This retrospective study included patients with laboratory-confirmed COVID-19 infection or clinical and radiological confirmed COVID-19 infection who were admitted to adult ICUs between March 18 and April 22, 2020. Demographic data, the recent exposure history, clinical symptoms, laboratory findings and comorbidities were recorded. Acute Physiology and Chronic Health Evaluation II (APACHE II) and Sequential Organ Failure Assessment (SOFA) scores were calculated. as well as mechanical ventilation parameters and blood gas results. Results: Twenty-four adult patients were admitted to the ICU with laboratoryconfirmed COVID-19 $(n=15)$ or clinical and radiological confirmed COVID$19(n=9)$. One or more comorbidities were detected in 22/24 of the patients. All patients had abnormal radiography imaging on admission. Twenty patients had bilateral ground-glass opacification on computerized tomography (CT) scan. Almost all patients (23/24) underwent invasive mechanical ventilation therapy. Three patients underwent noninvasive mechanical ventilation. Ten patients died. The mean length of ICU stay in patients who died was 9.6 \pm 9 days (2-18 days). The mean length of ICU stay of the four patients who were discharged from the ICU to the floor was $17 \pm 12.9$ days. The mean length of ICU stay of patients still in the ICU was $(\mathrm{n}=10)$ was $13.36 \pm 10.92$ days. Conclusion: The vast majority of patients admitted to the ICU with the diagnosis of COVID-19 have multiple co-morbidities, require ventilator support, and experience a high mortality rate.
\end{abstract}

\section{Keywords}

COVID-19, Intensive care, Viral infection

\section{Introduction}

Coronavirus $(\mathrm{CoV})$ epidemics have appeared from animal reservoirs to cause severe disease on three occasion in the 21 st century. Severe acute respiratory syndrome $\mathrm{CoV}$ (SARS-CoV) emerged in 2003 as the first international health emergency of the 21 st century, causing hundreds of people to die. Middle East respiratory syndrome $\mathrm{CoV}$ (MERS-CoV) from the CoV family, which has not been previously shown in humans or animals, was first described in humans in Saudi Arabia in September, 2012 [1, 2]. In late December 2019, the World Health Organization (WHO) China Country Office reported pneumonia cases of unknown etiology in Wuhan, Hubei, China. On January 7,2020 , the causative agent was identified as a new $\mathrm{CoV}$ (2019-nCoV), which has not previously been detected in humans. Subsequently, the name of 2019-nCoV disease was changed to COVID-19, and the virus was named as 
SARS-CoV-2 [3].

As of April 18, 2020, 2,321,385 confirmed COVID-19 cases were reported to the WHO from 213 countries with 156,620 deaths. Total COVID-19 cases and mortality were 82,329 and 1,890 respectively in Turkey on April 18, 2020 $[4,5]$. A shortage of medical masks and ventilators has impaired efforts to treat this viral panedemic. Generally low-income and middle-income countries have inadequate ICU beds and staff to contain such a pandemic [6].

The aim of this paper is to report the demographics, clinical features, comorbidities, imaging findings, and prognosis among critically ill patients with COVID-19 in the ICU of the Pamukkale University Medical Faculty, Turkey.

TA B L E 1. Demographics and Clinical Characteristics of the Patients at Admission.

\begin{tabular}{lc} 
Age & $65.5 \pm 13.9$ year \\
Sex (M/F) & $20 / 4$ \\
Smoking (+/-) & $10 / 14$ \\
\hline APACHE II score & $27.5 \pm 7.4$ \\
SOFA score & $9.8 \pm 3.1$ \\
Murray Score & $2.3 \pm 0.9$ \\
Admission service & 11 \\
Ward & 13 \\
Emergency & $3.58 \pm 2.28$ \\
\hline Length of stay for service (day) & $3.83 \pm 3.18$ \\
Duration of symptoms before ICU (day)
\end{tabular}

\section{Symptoms and signs}

\begin{tabular}{lc} 
Fever & 11 \\
Cough & 14 \\
Dyspnea & 19 \\
Fatigue & 5 \\
Travel history (yes/No) & 1 \\
\hline Contact history (yes/No) & 21 \\
Comorbidities & \\
Cardiovascular disease & 12 \\
Diabetes Mellitus & 9 \\
\hline Hypertension & 7 \\
Chronic renal disease & 6 \\
Chronic pulmonary disease. & 5 \\
Malignancy & 4 \\
\hline HIV & 1
\end{tabular}

Legend: $M=$ Male; $F=$ Female; $A P A C H E=$ Acute Physiology and Chronic Health Evaluation II; SOFA = Sequential Organ Failure Assessment; HIV = Human Immunodeficiency Virus.

\section{Material and methods}

After the Local Ethics Committee of the Pamukkale University, Medical School approval, this retrospective study was performed at the Pamukkale University Hospital. Informed consent was waived in light of retrospective design of the study. Researchers analyzed only anonymized data.

This study included patients with laboratory-confirmed COVID-19 infection or clinical and radiological confirmed COVID-19 infection who were admitted to the university hospital adult ICUs between March 18 and April 22, 2020. A confirmed case of COVID-19 was defined by a positive result on a reverse-transcriptase-polymerase-chainreaction (RT-PCR) assay or antibody Rapid Test of a specimen collected on a nasopharyngeal swab or endotracheal aspirate. Patient's data was obtained from electronic data stored in software in the hospital computers. Data were recorded by the intensivist on a daily basis.

\subsection{Data Collection}

Demographic data, the recent exposure and travel history, clinical symptoms or signs, laboratory findings and comorbidities were recorded. Acute Physiology and Chronic Health Evaluation II (APACHE II) and Sequential Organ Failure Assessment (SOFA) scores were calculated and recorded. Invasive mechanical ventilation parameters were also recorded. Radiologic assessments included chest radiography or computed tomography (CT), was performed at admission and as needed. Arterial partial pressure of oxygen $\left(\mathrm{PaO}_{2}\right), \mathrm{PaO}_{2} / \mathrm{FiO}_{2}$ ratio and acute respiratory distress syndrome (ARDS) were documented [7]. Sepsis and septic shock were defined and managed according established guidelines [8, 9] and the Turkey Ministry of Health recommendations for treatment of COVID-19 patients [10]. Microbial cultures from tracheal aspirates, blood and urine were taken at admission and throughout the hospital stay.

RT-PCR assays (COVID-19 RT-qPCR, Bio-Speedy) were performed in accordance with the protocol established by the WHO in this laboratory [11]. Coronavirus Disease (COVID-19) 1gM/1gG Antibody Rapid Test, Beijing Hotgen Biotech Co were used in some suspected patients.

The patients discharge status (dead, alive), and length of stay in the ICU were also recorded.

\subsection{Statistical Analysis}

Statistical analysis was performed with SPSS 25 software. Descriptive statistics were used to summarize the data; results are reported as medians and ranges or means and standard deviations. Categorical variables were summarized as counts and percentages.

\section{Results}

Twenty-four adult patients (18 years of age or older) were admitted to the ICU with laboratory-confirmed COVID-19 infection $(n=15)$ or clinical and radiological confirmed COVID-19 infection $(n=9)$. The first case was hospitalized 
TA B L E 2. Laboratory Parameters and Radiologic Findings of the Patients at Admission.

\begin{tabular}{lc} 
White blood cell count $\left(\right.$ per $\left.\mathrm{mm}^{3}\right)$ & $10900 \pm 5700$ \\
\hline Lymphocyte count $\left(\right.$ per $\left.\mathrm{mm}^{3}\right)$ & $920 \pm 1200$ \\
Platelet count $\left(\right.$ per $\left.\mathrm{mm}^{3}\right)$ & $205700 \pm 9700$ \\
Neutrophil to lymphocyte ratio & $13.4 \pm 14.6$ \\
D-dimer. $\mathrm{ng} / \mathrm{mL}$ & $1129.5 \pm 805.4$ \\
Creatinine. $\mathrm{mg} / \mathrm{dL}$ & $1.3 \pm 0.8$ \\
Lactate $(\mathrm{ug} / \mathrm{L})$ & $2.0 \pm 1.1$ \\
Ferritin $(\mathrm{ug} / \mathrm{L})$ & $698.0 \pm 647.9$ \\
Fibrinogen $\mathrm{mg} / \mathrm{dL}$ & $447.2 \pm 118.8$
\end{tabular}

\section{Radiography}

Normal 0

Bilateral infiltrates

8

Pleural effusion

Irregular opacities

5

\section{Computerized tomography}

Bilateral ground-glass opacification on CT 20

Pleural effusions on CT

Nodules

7

Legend: $C T=$ computerized tomography $(C T)$.

TA B L E 3. Ventilatory Parameters and Blood Gas Data of the Patients.

\begin{tabular}{|c|c|}
\hline \multicolumn{2}{|l|}{ At admission } \\
\hline PEEP, $\mathrm{cm} \mathrm{H}_{2} \mathrm{O}$ & $8,6 \pm 2,1$ \\
\hline $\mathrm{PaO}_{2} / \mathrm{FiO}_{2}$ ratio & $163,4 \pm 86,2$ \\
\hline $\mathrm{FiO}_{2}$ & $64,3 \pm 9,9$ \\
\hline $\mathrm{P}_{\text {peak }}$ & $29,4 \pm 4,1$ \\
\hline $\mathrm{P}_{\text {plato }}$ & $17,7 \pm 4,6$ \\
\hline Compliance $\mathrm{mL} \mathrm{cmH}_{2} \mathrm{O}$ & $51,7 \pm 26,7$ \\
\hline \multicolumn{2}{|l|}{ During ICU } \\
\hline Range of PEEP, $\mathrm{cm} \mathrm{H}_{2} \mathrm{O}$ & $5-14$ \\
\hline Range of $\mathrm{PaO}_{2} / \mathrm{FiO}_{2}$ ratio & $65-434$ \\
\hline Range of $\mathrm{P}_{\text {peak }}$ & $20-35$ \\
\hline Range of compliance $\mathrm{mL} \mathrm{cmH} \mathrm{cm}_{2} \mathrm{O}$ & $19-94$ \\
\hline
\end{tabular}

on March 15th with the complaint of fatigue and sore throat and was admitted to the ICU with respiratory failure on March 18th.

$83 \%$ of the patients were male. The mean age was 65.5 \pm 13.9 years. There was a domestic travel history in one patient, and a suspicious contact history in 21 patients. The vast majority of patients were hospitalized from the emergency department. The symptom duration of patients until the hospitalization was observed to be $3.83 \pm 3.18$ days. Except for one patient, all patients were admitted for respiratory failure and the need for mechanical ventilation. Fever, cough, respiratory distress, and weakness were the most common symptoms. Only 2 patients had a sore throat (Table 1).

One or more comorbidities were detected in $22 / 24$ of the patients. Cardiac disease, diabetes mellitus, hypertension, chronic lung disease, chronic kidney disease, and malignancy were the most common comorbidities. One patient was diagnosed with HIV. The disease severity scores were found to be high for APACHE II and SOFA scores. Data were shown in Table 1.

At the time of, the admission, the neutrophil to lymphocyte ratio was elevated and lymphocyte counts were lower. During the ICU stay, the highest values for D Dimer and ferritin were reported as $14515 \mathrm{ng} / \mathrm{mL}$ and 2241 $\mu \mathrm{g} / \mathrm{mL}$ respectively. The highest value for Neutrophil to lymphocyte ratio (NLR) was 67.2 during the ICU stay in 24 patients.

At admission, the CT scan in 7 patients showed a pleural effusion and bilateral ground glass areas, while 5 of these patients had no pleural effusions. All patients with a nodular appearance on the CT scan also had groundglass opacification. None of the patients had a normal radiograph. The laboratory values and radiological findings during the ICU stay are summarized in Table 2.

The majority of the patients (23/24) underwent invasive mechanical ventilation therapy. Three patients underwent noninvasive mechanical ventilation after invasive mechanical ventilation. A tracheostomy was performed in 3 patients. One patient received noninvasive mechanical ventilation and oxygen therapy with a mask. The majority of $\mathrm{PaO}_{2} / \mathrm{FiO}_{2}$ values during the ICU stay were compatible with moderate to severe ARDS. During the ICU stay, ventilator parameters ranged from $5-14 \mathrm{cmH}_{2} \mathrm{O}$ for PEEP, 65-434 for $\mathrm{PaO}_{2} / \mathrm{FiO}_{2}, 20-35 \mathrm{cmH}_{2} \mathrm{O}$ for Ppeak and 19$94 \mathrm{cmH}_{2} \mathrm{O}$ for compliance (Table 3 ). Thick endotracheal secretions were observed in 22/24 of the patients. During hospitalization, 9 patients underwent a recruitment maneuver and5 patients were placed in a prone position.

All patients were diagnosed with ARDS and 7 patients were diagnosed with sepsis during their ICU stay. Thirteen of the patients received Hydroxychloroquine sulfate (Plaquenil/generic), 16 of the patients received antivirals (Enfluvir, Kaletra, Favipiravir), and all of the patients received antibiotic therapy. Mesenchymal stem cell therapy was performed in 1 patient. Seventeen of the patients received vasopressor treatment. Renal replacement therapy was performed in 12 patients with kidney failure. Cytokine removal was performed in 2 patients during renal replacement therapy. The IL 6 receptor antagonist Tocilizumab (humanized monoclonal antibody against the interleukin-6 receptor (IL-6R) was given to 4 patients.

Ten patient in the study died. The mean length of ICU stay in patients who who died was $9.6 \pm 9$ days (2-18 days). The length of ICU stay of four patients who were discharge to the ward was 22 days, 32 days, 2 days and 12 days. The 
mean length of ICU of patients still in the ICU was $(n=10)$ was $13.36 \pm 10.92$ days.

\section{Discussion}

This study presents the critically ill patients admitted the ICU with laboratory or clinical/radiological confirmed COVID-19 from March 18 to April 22, 2020 in a university hospital. These patients required a high rate of mechanical ventilation and high levels of PEEP $[12,13]$.

Common symptoms of COVID-19 disease are respiratory symptoms, fever, cough, and dyspnea. In more serious cases, pneumonia, severe acute respiratory infection, kidney failure, and even death may develop [14]. 138 patients with COVID-19 in Wuhan, China were evaluated in a recent study, 36 of them admitted to the ICU. The median age of the ICU patents was 66 years. Patients in the ICU were significantly older and had more underlying comorbidities than patients who did not require ICU care [15]. Grasselli $\mathrm{G}$ et al [16] evaluated baseline characteristics and outcomes of more than fifteen hundred patients infected with COVID19 in ICUs in Italy. In their study, the median age was 63 years. $23 \%$ of the patients were aged 71 years and older. The most common comorbidities were hypertension and cardiovascular disease. In our study, almost all patients were admitted to the ICU because of the need for increased respiratory care. The median age was $65.5 \pm 13.9$ years. The mean length of symptoms before ICU admission was $3.83 \pm 3.18$ weeks. The majority of patients were admitted directly from the emergency room to the ICU. In our study, APACHE II and SOFA scores were very high in this population similar to Chinese studies $[13,15]$. The most common symptom in the ICU was fever similar to the China and Lombardy studies $[15,16]$. In our study, the most common comorbidities were diabetes mellitus, heart disease, chronic pulmonary disease, chronic kidney disease put space between words.

In the Wuhan ICU study, $44 \%$ of patients received noninvasive ventilation and $11 \%$ of patients received highflow nasal cannula. 17 patients $(47 \%)$ required invasive mechanical ventilation [15]. Grasselli $\mathrm{G}$ et al [16] reported that 1300 patients received respiratory support; $88 \%$ of whom required invasive mechanical ventilation, and $11 \%$ of whom received noninvasive ventilation. The median PEEP and maximum PEEP were $14 \mathrm{cmH}_{2} \mathrm{O}$ and $22 \mathrm{cmH}_{2} \mathrm{O}$ respectively. The median ratio of $\mathrm{PaO}_{2} / \mathrm{FiO}_{2}$ was 160 . The need for invasive mechanical ventilation in the Italian study [16] was higher than reported for otherstudies: Washington State, US (71\%) [12] and China (47\%) [15]. In our study invasive mechanical ventilation were required in $95 \%$ of the patients and $16 \%$ of the patients were managed with noninvasive ventilation.

In the diagnosis of COVID-19, clinical findings should be evaluated together with laboratory and radiological findings. In accordance with the available literature lymphocytopenia was common in our patients. Bilateral pneumonia is reported up to $100 \%$ of cases on chest radiography $[15,17]$. In accordance with the literature, there was no normal radiography imaging in our patients. The bilateral patchy shadowing, ground-glass opacity, a peripheral distribution, fine reticular opacities, and vascular thickening were reported on the chest CT [17]. Chest CT imaging is a reliable, practical, and rapid method to diagnose and evaluate COVID-19 when compared to RT-PCR [18]. Many factors can affect the reliability of the RT-PCR test, such as the quality of sample collection, stages of infection and quality of the PCR tests being used. Diagnostic RTPCR test sensitivity may vary in the range of $45 \%$ and $67 \%$ [19]. Therefore, we have put space between words and/or radiologic suspected COVID-19 cases in this study. One patient was diagnosed with HIV. It was thought that negative results of the diagnostic tests in this patient might be related to host immune status because of the HIV.

Currently, there is no specific treatment for COVID-19 that has proven safety and efficacy. In order to find an effective treatment for this disease, more than 300 active clinical treatment trials are underway with a large number of drugs, some of which are expected to be announced in the coming months [20]. In pharmacologic therapy, mainly Hydroxychloroquine sulfate, antivirals, Azithromycin 500 $\mathrm{mg}$ tablet and antibiotics according to the culture results were used.

Different mortality rates were reported in a range of $16 \%$ $88.1 \%$ in previous studies for COVID-19 patients requiring ICU care (12-16.21). $58 \%$ of the patients were in the ICU in the largest case series from Italy (provide the citation). Richardson et al [21] reported a $88.1 \%$ mortality rate among mechanically ventilated patients from New York. $72 \%$ of the patients requiring mechanical ventilation in this study remain in the hospital and were excluded from mortality analysis. It is also not possible to give an exact mortality rate in our study. Until now, most of the published papers have stated mortality rates which are inconclusive because many ICU patients remain hospitalized and their ultimate prognosis is unknown. tments. More long-term outcome data will be necessary to determine which therapies are more successful in decreasing the mortality rate in these ICU patients.

Our study has several limitations. First, it was derived from a small number of patients from a single center. Second, ten patients are still hospitalized in the ICU at the time of the manuscript submission, and length of stay in the ICU and mortality may vary when we include their data.

In summary, we have found that the management of COVID-19 patients requiring ICU care have multiple comorbidities, require ventilator support, and experience a higher mortality rate.

\section{ACKNOWLEDGEMENTS}

I would like to thank Ferruh Niyazi Ayoğlu, Professor MD, Dept of Public Health, Bulent Ecevit University for his valuable advice in the statistical analysis. 


\section{CONFLICT OF INTEREST}

The authors declare that they have no competing interests.

\section{AUTHORS CONTRIBUTIONS}

UA, CÖ, IHA conceptualization, data collection, formal analysis, investigation, methodology, HS writing the original draft, review and editing, MK, HE, HA, SK data collection,All authors read and approved the manuscript.

\section{ETHICS APPROVAL}

Informed consent was waived in light of the urgent need to collect data: It was approved by the local ethic committee.

\section{FUNDING INFORMATION}

The funding bodies had no role in the design of the study and collection, analysis, and interpretation of data and in the writing of the manuscript.

\section{AVAILABILITY OF DATA AND MATERIAL}

The data that support the findings of this study are available from Pamukkale University but restrictions apply to the availability of these data and so are not publicly available.

\section{REFERENCES}

[1] Cui J, Li F, Shi ZL. Origin and evolution of pathogenic coronaviruses. Nat Rev Microbiol. 2019;17:181-92.

[2] De Wit E, van Doremalen N, Falzarano D, Munster, VJ. SARS and MERS: recent insights into emerging coronaviruses. Nat Rev Microbiol. 2016;14:523-34.

[3] https://www.who.int/csr/don/ 12-january-2020-novel-coronavirus-china/en/ . accessed 13 Apr 2020.

[4] https://tr.wikipedia.org/wiki/Turkiye\%27de_2020_ koronavir\%C3\%BCs_pandemisi\#cite_note-aa-8. accessed 18 Apr 2020.

[5] https://www.worldometers.info/coronavirus/, accessed 18 Apr 2020.

[6] Phua J, Weng L, Ling L, Egi M, Lim CM, Divatia JV, et al. Intensive care management of coronavirus disease 2019 (COVID19): challenges and recommendations. Lancet Respir Med. 2020.

[7] Ranieri VM, Rubenfeld GD, Thompson BT, Thompson Tb, Ferguson ND, Caldwell E, et al. Acute respiratory distress syndrome: the Berlin Definition. JAMA. 2012;307:2526-33.

[8] Singer M, Deutschman CS, Seymour CW, Msc MS, Annane D, Bauer
$\mathrm{M}$, et al. The third international consensus definitions for sepsis and septic shock (Sepsis-3). JAMA. 2016;315:801-810.

[9] https://www.sccm.org/getattachment/Disaster/ SSC-COVID19-Critical-Care-Guidelines .pdf . accessed 18 Apr 2020.

[10] T. C. Ministry of Health general directorate of public health, COVID-19 (SARS-CoV-2 infection guide, Ankara. 2020. accessable on: https://covid19bilgi.saglik.gov.tr/depo/tedavi/ COVID19-EriskinHastaTedavisi.

[11] World Health Organization. Coronavirus disease (COVID-19) technical guidance: laboratory testing for $2019-\mathrm{nCoV}$ in humans. 2020. accessable on: https://www. who/int/emergencies/ diseases/novel-coronavirus-2019/technical-guidance/ laboratory-guidance.

[12] Arentz M, Yim E, Klaff L, Lokhandwala S, Riedo FX, Chong M, et al. Characteristics and outcomes of 21 critically ill patients with COVID-19 in Washington State. JAMA. 2020.

[13] Yang X, Yu Y, Xu J, Shu H, Xia J, Liu H, et al. Clinical course and outcomes of critically ill patients with SARS-CoV-2 pneumonia in Wuhan, China: a single-centered, retrospective, observational study. Lancet Respir Med. 2020;8:475-481.

[14] Huang C, Wang Y, Li X, Ren L., Zhao J, Hu Y, et al. Clinical features of patients infected with 2019 novel coronavirus in Wuhan, China. Lancet. 2020;395:497-506.

[15] Wang D, Hu B, Hu C, Zhu F, Liu X, Zhang J, et al. Clinical characteristics of 138 hospitalized patients with 2019 novel coronavirusinfected pneumonia in Wuhan, China. JAMA. 2020;323:1061-1069.

[16] Grasselli, G, Zangrillo, A, Zanella A, Antonelli M, Cabrini L, Castelli A, et al. Baseline Characteristics and Outcomes of 1591 Patients Infected With SARS-CoV-2 Admitted to ICUs of the Lombardy Region, Italy. JAMA. 2020.

[17] Bai HX, Hsieh B, Xiong Z, Halsey, K, Choi, JW, Tran, TML, et al. Performance of radiologists in differentiating COVID-19 from viral pneumonia on chest CT. Radiology. 2020.

[18] Ai T, Yang Z, Hou H. Correlation of Chest CT and RT-PCR Testing in Coronavirus Disease 2019 (COVID-19) in China: A Report of 1014 Cases. Radiology. 2020;26:200642.

[19] Zhao J, Yuan Q, Wang H, Liu W, Liao X, Su Y, et al. Antibody responses to SARS-CoV-2 in patients of novel coronavirus disease 2019. Clin Infect Dis. 2020.

[20] Sanders JM, Monogue ML, Jodlowski TZ, Cutrell JB. Pharmacologic Treatments for Coronavirus Disease 2019 (COVID-19): A Review. JAMA. 2020.

[21] Richardson S, Hirsch JS, Narasimhan M, Crawford JM, McGinn T, Davidson KW, et al. Presenting Characteristics, Comorbidities, and Outcomes Among 5700 Patients Hospitalized With COVID-19 in the NewYork City Area. JAMA. 2020.

How to cite this article: Hülya Sungurtekin, Ülkü Arslan, Cansu Özgen, İsmail Hakkı Akbudak, Mithat Kahramanoglu, Hakan Erbay,et al. Prognosis of COVID-19 Patients Requiring Intensive Care Unit Care List all the Authors and Their Affiliations. Signa Vitae. 2020;16(1):147-151. doi:10.22514/sv.2020.16.0019. 